\title{
10 Conclusion. Reflections on Present and Future: towards an Ontological Approach to LMOOCs
}

\begin{abstract}
This concluding chapter gives an overview of the affordances and weaknesses of LMOOCs mentioned in the previous chapters, before situating them in a larger framework of ontological specification. A second angle of attack is to test LMOOCs from an educational engineering point of view. Finally, directions for LMOOC research are given in the light of current CALL research challenges. LMOOCs will or will not survive depending on their genuine ontological specification.
\end{abstract}

Keywords: ontologies, LMOOCs, design, research challenges

"El mundo era tan reciente que muchas cosas carecían de nombre, y para mencionarlas había que señalarlas con el dedo.”

"The world was so recent that many things lacked names, and in order to refer to them it was necessary to point at them with your finger."

(G.G.Márquez, Cien años de soledad)

\subsection{Introduction}

The previous chapters offer a kaleidoscopic view on LMOOCs from a wide array of perspectives such as design, motivation, effectiveness, pronunciation, the teacher's role and accessibility, while focusing on methodological, ethical, aesthetic, architectural and social aspects. This phenomenological richness - and complexity at the same time - constitutes immediately in my view the main characteristic of LMOOCs.

First I will try to summarize the points mentioned by the contributors to this volume in terms of strengths, weaknesses, opportunities and threats. I will then discuss the need for a common terminology based on well-defined concepts which we call ontologies, and evaluate to what extent the acronym LMOOC stands for unambiguous concepts. The LMOOC as concept will then be tested against Educational Engineering, my personal approach, and against current research challenges in CALL, as recently discussed in our community.

Finally, I will try to formulate some concrete lines of action for LMOOCs. When taking into account what has gone before in CALL research and development, when analyzing the current research context and when gauging future developments, it 
is clear that LMOOCs can play an important role in language learning and teaching worldwide. They can. Provided we play the game seriously, leaving aside all false reasoning, reassuring lies, myths and hypes; simply by respecting the teacher, the learner, the content provider and the researcher; by respecting what we have learned in the early years of CALL.

\subsection{To MOOC or not to MOOC, that's the Question}

MOOCs emerged very rapidly, with a promising aura of open and free education - or at least access to education-for the entire world, or at least on a massive international scale. And this phenomenon is particularly remarkable when we compare it with the effort, cost and energy it took to 'sell' Interactive Whiteboards (IWBs), language courseware or Student Response Systems. Where has all the funding suddenly come from? Who is behind all this? And I am not the only one to be surprised by the (L)MOOC wave. Beaven et al. in their chapter call it an 'education bonanza' we are just beginning to understand and they invite all of us to make sense of this new phenomenon.

So what are the strong points of the (L)MOOCs? Whereas xMOOCs fit a more traditional approach in language courseware, cMOOCs fit recent approaches in educational theory, such as constructivism, connectivism, dynamic complex system theory and task-based learning. Mota in this volume for instance states that LMOOCs open up language education to Large Communities of Practice. iMOOCs more specifically favour collaborative learning experiences and focus on empowering individual learners. Castrillo agrees that they provide the best example of collaborative learning based on the connectivist and collective intelligence theories. Read in his chapter mentions that (L)MOOCs should be more than Virtual Learning Environments (VLEs), and that the social dynamics of such courses foster peer interaction. Finally, Rubio shows a larger effect size for LMOOCs, mainly through implicit and explicit feedback, but adds as a caution that the results of his study did not imply that LMOOCs are a better format than F2F courses.

The contributors to this volume repeatedly expressed the need for taking into account particular requirements in order to avoid specific pitfalls. Rodrigo, for instance, reminds us that the success of learning with MOOCs is highly dependent on human interaction and on their digital skills in using the platform, the multimedia content and social technologies. Read states that we should bring together the best of both formal and informal learning, combining structured learning content with activities based on appropriate social media, tools and technologies. Mota reminds us that the quality of the learning experience should entail student satisfaction, and Beaven et al. focus on good design, on motivation and on how to avoid frustration. Rodrigo adds usability and accessibility criteria for people with visual, auditory and physical disabilities. Álvarez in her chapter explains how and why the context, the 
content, the medium and the agents should be taken into account from an ethical and aesthetic perspective. Castrillo focuses on the changing teacher's role: course manager, forum curator, administrator, researcher... All authors agree that LMOOCs are a young phenomenon and that much is open for experimentation. This volume brings together the needed requirements for doing so in a justifiable way.

On the downside, Rubio states that resistance in the profession might be an important issue. Language teachers seem to be "on the fence", and slow in embracing the concept of massive courses, concerned about practical and methodological implications of teaching online. And this sets the tone for a set of weaknesses and threats which might jeopardize the future of LMOOCs. Read warns us for the technological complexity of LMOOCs. But at the same time that technological complexity does not offer us enough linguistic-didactic functionalities. Sokolik agrees that we need a more nuanced set of communication and assessment tools. Beaven et al. state that, in order to engage in social learning of language skills, a high level of interaction is difficult to achieve. But the main problem might be deeper than merely technological, namely design-related. Mota speaks about poor design, Beaven et al. notice that little research has been conducted into the profile of participants, and Read ends up enumerating all aspects that can go wrong in bad design.

Finally, when the contributors to this volume look at what has happened so far, they are unable to avoid the observation that LMOOCs have mainly been initiated by elitist universities and that current users are mainly motivated, well-educated students and that drop-out rates are too high (or, conversely, completion rates are far too low).

\subsection{Ontology of the LMOOC}

Building on the preceding observations, I have tried to formulate some personal considerations which are based on my experience as language teacher and as courseware developer, and on my theoretical knowledge as researcher, but also and perhaps mainly, on plain common sense.

\subsubsection{Blurred Ontologies: Pervasive but Persuasive}

First of all, any self-respecting discipline should work on a domain-specific terminology which reflects a coherent set of common concepts. This is obvious in law, medicine, technology and economy, but less in 'softer' or younger disciplines such as pedagogy, instructional design and computer assisted language learning. Recent attempts to conceptualize learning objects (LOs), for instance, have been subject to criticism: 
It is evident that LOs are the most meaningful and effective way of creating content for e-learning. Unfortunately, the current definitions and practices of LOs are confusing and arbitrary. Consequently, they will never be able to avail themselves of the flexibility, scalability and speed offered by information technology. To break from this impasse, a commonly accepted, accurate and functionally effective definition of a LO is an immediate necessity. (Polsani, 2006).

In CALL, very few domain-specific terms exist, let alone terms based on common concepts and used within the same acceptation. In a larger realm, terms like flipped classrooms, blended learning, digital pedagogy, design-based research, serious games, bring-your-own-device (BYOD), digital natives and Virtual Learning Environments (VLEs) are examples of blurred ontologies. Each of these terms has probably been coined by a researcher who just wanted to give a name to a new and largely unknown phenomenon, and who was surprised to see that the term was being picked up so quickly by so many peers. There is no conference presentation, no article without at least one of these terms in the abstract. The problem is that no one remembers the originally intended meaning, and each uses these terms with a different meaning in mind. Eventually, they have become pervasive, but empty and meaningless at the same time. They continue to be used in a persuasive discours, mainly when policy makers try to invent or defend their raison d'être. Language teachers have no other choice than to follow them. By speaking the lingo they find a way to justify the way they teach. Psychologically speaking, this should work in a reassuring and supporting way. But it might entail unexpected side-effects if the methodological tenets and conceptual specifications are flawed.

Language teachers believe, because now there is technology, that they should flip their classrooms. We should tell them there is no need for flipping the classroom. What they should do is (learn to) design their learning environment. And that might entail reshuffling some activities in and outside the classroom.

Blended learning is a term to be avoided at all cost. It is mainly being used by teachers who do not change anything in their teaching, but simply add some interactive exercises in Moodle, Blackboard or Hot Potatoes. "My teaching is OK because I do blended learning. My teaching is blended because I added some interactive exercises." What we should do is to try to convince teachers that good design can yield a wide panoply of surprising, enabling and empowering functionalities which exceed by far their expectations.

I could go on as regards the other terms mentioned above as well, but I will leave that for another publication. At any rate, my first recommendation would be to start working together on a common CALL terminology, and to situate the concept of an LMOOC within this endeavor. 


\subsubsection{The LMOOC as Ontology}

Let us look now at the LMOOC from an ontological point of view. As LMOOC stands for Language Massive Open Online Course, we should start with an analysis of each of these terms.

- L: Language. LMOOCs do offer interesting affordances which fit Second Language Acquisition (SLA) and constructivist theories, but it is our impression that current LMOOCs do not build upon what has gone before, ignoring even functionalities which should be considered as basic.

How many MOOCs are dedicated to language learning? How many tools for creating MOOCs (such as Moodle, Coursera, Wiziq, Elgg, Udacity and Edx) contain features specifically designed for language learning and teaching? To what extent do LMOOCs take into account accepted requirements in terms of linguistic-didactic functionalities (Colpaert, 2004) such as corrective feedback (Cornillie et al., 2012), error analysis, remediation, pronunciation training (van Doremalen, 2014), intelligent tutoring, collaborative writing...?

So far, the L in LMOOCs has not been conceptualized strongly yet. In order for an LMOOC to be accepted by our discipline, it should first meet some clearly specified requirements in advance.

- M: Massive. The M in LMOOCs stands for massive or 'intended for large user groups'. But given the reported user types (only higher educated, motivated students) and the high drop-outs, can we still call them massive in terms of 'market penetration'?

Secondly, why should they be massive? The only reason for developing massive courses would normally be to reduce the development cost per paying participant. But the higher the number of users, the less adaptation to individual differences or (sub)-group characteristics, the lower the support, feedback and control. Or does Massive also apply to content size, the number of linguistic-didactic functionalities, the range of learning paths, the set of task types, the number of actors and stakeholders in the learning ecology, etc.?

A way to better conceptualize the M in LMOOCs would be to apply 'massive' to the requirements formulated under $\mathrm{L}$ in the first place.

- 0: Open. LMOOCs and MOOCs in general are called Open, which they are not. They are accessible, usable and, in the best of cases, free. They are not Open in the light of Open Source, Open Data and Open Knowledge movements: "A piece of data or content is open if anyone is free to use, reuse, and redistribute it - subject only, at most, to the requirement to attribute and/or share-alike.” This definition of 'open' by the Open Knowledge Foundation is given on http://opendefinition. org/od/. If any teacher can take a set of exercises (or any other content type) out of a MOOC, implement it elsewhere, edit and improve it, and put it at the disposal again of other colleagues worldwide, then we would have Open content. The content of most MOOCs is not even generic nor sustainable (as defined in 
Colpaert, 2013). So the $\mathrm{O}$ in LMOOCs seems to me by far the weakest aspect in terms of clear conceptualization.

- 0: Online. In the minds of many, the ontology of 'online' is mainly related to 'made accessible by putting it on a server in some kind of digital environment'. Online systems, however, afford in my view two of the strongest technological properties that we have seen in recent years: namely, personalization and contextualization. Personalization means adaptation of the course in terms of degrees of freedom, learner/system control, structure and progression, task types, learning styles, topics, support, feedback, peer interaction, layout or difficulty level. This adaptation can easily be calculated as a function of learner analytics of the total user group, subgroup characteristics and individual differences. Contextualization means adaptation to the geo-temporal context of the learner, mainly in terms of selecting tasks on context-relevant content. This adaptation can be calculated based on local time, GPS location, GPS history and a set of hypothesized next locations based on that history.

Seemingly, both personalization and contextualization are not yet properties in this 'online' ontology.

- C: Course. Then finally, what do we mean by course? A tool for self-realization or a device for obtaining some kind of certification (diploma, degree, certificate ...)? Secondly, how many existing LMOOCs are linked to the levels of the Common European Framework (CEFR)? Finally, how do existing LMOOCs determine the appropriate degree of learner control, system control or teacher control? In other words: how have LMOOCs been designed so far? On the basis of which methodological and justifiable design model?

\subsection{LMOOCs from an Educational Engineering Point of View}

Educational Engineering is an instructional design model for designing, developing, implementing and evaluating educational artefacts such as documents, tools, content, concepts, models and solutions such as textbooks, syllabi, lesson plans, curricula, graded readers, exercises, tests, applications or electronic learning platforms. It is a cyclic, iterative phenomenon that reformulates new hypotheses at every loop, based on the validation of the previous hypothesis combined with theory and practical experience. (Colpaert, 2014)

My personal research focuses on a number of hypotheses to be validated empirically and theoretically. Three of them are genuine paradigm shifts in my view as they require a totally different angle of attack for looking at the role of technology in language learning and teaching.

The ecological paradigm shift states that no technology carries an inherent, measurable and generalizable effect on learning. This targeted effect can only come from the entire learning ecology, defined as a dynamic set of interacting components such 
as content, actors and stakeholders, learning model, teaching model, evaluation model, technology and infrastructure. This changes the way we look at technology: we do not expect an IWB to have an effect on learning, but we might decide to use an IWB (Van Laer et al., 2012.) in order to increase the effect of the learning environment we are creating. In the case of LMOOCs, the problem is that normally the MOOC is the learning environment itself if no other learning or teaching activities are foreseen.

The design-process paradigm shift states that the eventual effect of the learning environment will be proportional to its design, meaning the extent to which it has been designed in a methodological and justifiable way. In other words, we should stop ticking feature boxes in order to evaluate a specific technology. We should stop looking at the product, and start scrutinizing the process. An educational engineer will ask: "What was your rationale for developing the LMOOC? Which steps did you follow, how and why?". An educational engineer is like a chef, more interested in the recipe than in the look-and-feel of a dish. Currently, there are no data available on the design process of existing LMOOCs, nor on the tools for developing them.

The third paradigm shift is the psychological paradigm shift (Colpaert, 2010). It states that exclusive or exaggerated focus on pedagogical (or learning) goals - in case of problematic motivation - can be counterproductive. The lower the motivation, the more focus should be put on personal goals during the design process. Personal goals can be defined as subconscious volitions which are difficult to elicit. Colpaert (2010) describes a technique for doing so, and for defining personas or learner-types with common goals as the basis for their design. This Personal Goals Approach remains between Self-Determination Theory (Ryan \& Deci, 2000) and Dörnyei’s L2 SELF model (Dörnyei \& Ushioda, 2009).

Designers of any technology should ask themselves questions on three levels: (a) what is common for the entire group of learners? (b) which sub-groups with specific common personal goals can be defined?, and (c) which individual differences should be catered for? LMOOCs could, in my view, very easily take into account these requirements in the following way: (a) their general design should reflect the target group and the learning goal; (b) they should reflect the way it takes into account subgroup differences in terms of e.g. autonomy (need for support), collaboration (peer interaction) and expected rewards; and (c) the system should adapt to personal differences based on an analysis of learner behavior and performance. Now, the design of LMOOCs and MOOCS in general mainly reflects the design of the tool used, assuming some globally applicable learning and teaching model. There is not even adaptation to the subject matter, let alone the targeted user group. In my view, this could be one of the elements in play to explain the high drop-out figures. 


\subsection{LMOOCs from a CALL Research Point of View}

The theme of the XVIth International CALL conference in Antwerp in 2014 was "Research Challenges in CALL" (Colpaert et al., 2014). The starting points were the challenges I had already presented at WorldCALL 2013 in Glasgow during my keynote "Sustainability \& Research Challenges in CALL. I identified four contextual, four methodological and four epistemological challenges.

The main contextual challenge lies in the low academic value of CALL activities (Colpaert, 2012b). Developing an LMOOC will hardly be recognized as research when the design of the tools for making MOOCs cannot be changed to a significant degree. The analysis of learner analytics, on the contrary, might constitute a significant data corpus for further analysis. However, if a system is not optimally designed, does it make much sense to analyze its use and usage, with or without quantitative and qualitative triangulation?

The methodological challenges were presented as Design, Replication, Slow Research and Transdisciplinary. Design should be recognized and valued as research, and in the case of Educational Engineering, also as a specific research method (Colpaert, 2014). Replication of research designs in other contexts (Chun, 2012) is necessary in CALL because (a) it is a young discipline and (b) "when we give proper weight to local conditions, any generalization is a working hypothesis, not a conclusion." (Cronbach, 1975, p.125). CALL research is Slow Research by definition, as project findings only lead to readjusting probabilities in hypothesis validation (Bayesian epistemology) and not necessarily to self-standing publications. Finally, CALL is by definition a multidisciplinary endeavor. The best way to bridge the gap between disciplines is not to build multidisciplinary teams, nor to acquire each other's knowledge, skills and terminology, but to build together new concepts, methods and frameworks across disciplines. LMOOCs are extremely susceptible to these methodological challenges. LMOOC research should focus on the design process, replicating it in as many contexts as possible, gradually formulating, adjusting and validating new hypotheses along the way. These hypotheses should be formulated in a trans-disciplinary way ('above' the disciplines involved), mainly focusing on common concepts and terminology.

The four epistemological research challenges are described by four adjectives: Sustainable, Open, Psychological and Smart. The development of applications and systems for language learning and teaching is extremely labor-intensive. Both software components and content should, therefore, be conceived in a Sustainable way (Colpaert, 2013). Not only generic, reusable, transportable, scalable and exchangeable, but also Open. Not only should software (components) be open in the genuine spirit of Open Source, but also content should be developed in a co-constructive way. Thirdly, even in marketing, researchers acknowledge increasingly often that subconscious psychological factors play an important part in human behavior, that these factors are difficult to identify, and that traditional surveys or explicit questioning techniques fail in identifying them. The interest in psychological factors in design has 
been increasing and is reflected in approaches such as the Technology Acceptance Model (Venkatesh, 2000), Personal Goal Theory (Colpaert, 2010) and the Unified Theory of Acceptance and Use of Technology (Venkatesh et al., 2012). Finally, the Smart challenge points at the need to focus on specific affordances of online, mobile and location-aware devices, instead of trying to develop complex intelligent systems, especially in terms of the earlier mentioned personalization and contextualization. As to these epistemological challenges, we can say current LMOOCs score low - so low that they run the risk of disappearing if no drastic measures are being undertaken.

The first aspect that should be dealt with is co-construction of content. Consider LMOOCs as a kind of Open Educational Resource (OER). This is, in my view, the most powerful and at the same time most problematic aspect of LMOOCs. My main concern arises from earlier indications, which I presented at CALICO 2012 (Notre Dame University) and at the Joint EuroCALL CMC and Teacher Education Special Interest Group in Bologna (Colpaert, 2012a). The OER approach should normally lead to 50\% less work and 200\% more results for language teachers. That is certainly the impression one might have. But the least we can say is that teachers do not respond massively to these exciting affordances. We can even speak of a total lethargy towards OERs, the 'happy few' left aside. The question is: how can we explain this phenomenon? Next to easily identifiable aspects such as juridical problems (yes, but now we have Creative Commons), technological issues (there are, indeed, still not enough collaborative writing tools for co-constructing language learning content with sufficient linguistic-didactic functionalities) and epistemological considerations (what does "open” mean: accessible, reusable, changeable, redistributable?). There are psychological issues faced by teachers which are, in my view, priority research questions. Is it their fear that other colleagues may profit from their work as teachers? Is it the fear that their work may not be considered good enough by others? Do they realize that their work might not be adaptive enough to other contexts? Or is it the teachers' societal image which is at stake (again)? With OERs, teachers don't have anything to do anymore... The fear of being even less respected than now... Who will tell?

\subsection{The Suggested Path for LMOOCs}

How would an LMOOC look like if we took into account relevant findings or at least indications in CALL, if we took into account development cost and drop-out rates, and if we applied a decent design methodology? How should an LMOOC look like? In my view, an LMOOC should look like it has been well designed in a methodological and justifiable way, with its eventual features depending on local context and learning goal.

After having read the preceding chapters, and screened this reported status quaestionis against my design and research principles, I am still convinced that LMOOCs are a fascinating phenomenon, and that they offer tremendous opportunities for language 
learning and teaching worldwide. However, at the same time, I am convinced that it will take drastic decisions to turn the direction of this runaway oil tanker. So many aspects have been neglected (rationale, design, targeted audience...), so many findings ignored. I feel some cognitive dissonance and even emotional friction, not to say it distresses me to see what could have happened with a little more insight, creativity and method. And no, I will not fall into the trap of trying to sum up the boxes to be ticked as required features to determine the value of an LMOOC. LMOOCs should be polymorphous, adapted to their learning goals, learner types, context, etc. But they can be designed in a methodological, systematic, globally accepted way. And LMOOC research should focus on this research process: how to improve it, how to measure improvement, and how to formulate the next design hypothesis.

The following process indicators seem to me to be suitable for hypothesis testing purposes: Modularity, Specialization, Adaptation and Coconstruction. Modularity means that we can try to conceptualize the LMOOC not only as an entire course, but also as a set of concrete OER modules which can be easily implemented in any other learning environment, with or without additional face-to-face or classroom activities. Specialization means that LMOOCS should not try to serve as many users a possible, but as many learners who have the same learning goals as possible. The more concrete this goal, the better the LMOOC can respond to their needs: Academic English, Le Français des Affaires, Español para Hostelería,... Combined with the first modularity hypothesis, this would result in handy LMOOCs (almost apps) on speaking skills in Japanese, Dutch pronunciation training, writing scientific articles, negotiating in German, eating in Flanders etc. My third hypothetical requirement would be adaptation. We can situate this adaptation on three levels: (a) the general LMOOC design should be based on a thorough analysis of the targeted learner group (learner analytics), and not on a vague assumption of expected user behavior influenced or not by some kind of pedagogical theory; (b) the LMOOC design should offer different learning paths, task types, feedback, level and support which suit best the identified learner types, personas or user groups; and (c) the system itself should adapt to individual differences such as learning styles, learning tempo, preferred look-and-feel and accessibility issues. Finally, the co-construction issue, despite the earlier mentioned problems to consider LMOOCS as OERs, needs to be solved as this is certainly the only way LMOOCS will be able to survive.

\subsection{Conclusion}

LMOOCs are an intriguing phenomenon with promising theoretical affordances ranging from offering free education to challenged learners worldwide, over offering specialized courses tailored to the learners' needs, to provide course designers with huge collections of building blocks. 
LMOOCs are a recent phenomenon and they have emerged quite rapidly. It seems. They say. But how many LMOOCs do we actually know? In the early years of CALL, there were more people evaluating CALL applications or writing about how to do it, than people actually developing CALL applications. I have the impression that this emergence of MOOCS has also more to do with people speaking about them, and creating expectations, than people actually designing and developing them.

Furthermore, MOOCs are subject to a number of tensions. Tensions between market expectations and technological limitations, between requirements and affordances, between the individual and the global learner, between pedagogical theories and practical expectations, between free sponsored access and paid tuition.

In this volume, we have looked at LMOOCs from a wide variety of perspectives in order to show their richness and complexity. But at the same time, we have stated that the LMOOC is a blurred ontology (like so many other terms in the realm of educational technology), so the biggest challenge might be to try to work together on its conceptualization. Perhaps we might even need to find a new, more precise, name for it.

I am convinced that early developers of LMOOCs, even if the reason behind their emergence is not value-free, are laying the foundation for a remarkable development in the field of CALL. I am convinced that the authors of this volume have contributed to the much needed peer discussion. I am convinced that this volume will be considered a milestone in LMOOC history.

\section{Bibliography and Webliography}

Chun, D. M. (2012). Replication studies in CALL research. CALICO Journal, 29(4), 591-600.

Colpaert, J. (2004). Design of online interactive language courseware: Conceptualization, specification and prototyping. Research into the impact of linguistic-didactic functionality on software architecture (Doctoral dissertation). Antwerp, Belgium: University of Antwerp.

Colpaert, J. (2010). Elicitation of language learners' personal goals as design concepts. Innovation in Language Learning and Teaching, 4, 259-274.

Colpaert, J. (2012a). Open educational resources for language teachers: A goal-oriented approach. In Proceedings of the joint CMC and Teacher Education EuroCall SIGs Workshop Bologna, 29-30 March 2012. Retrieved from http://eurocallsigsbologna.weebly.com/papers.html

Colpaert, J.. (2012b).The "Publish and Perish" Syndrome. Computer Assisted Language Learning. Vol. 25, No. 5, December 2012, 383-391. (http://www.tandfonline.com/doi/pdf/10.1080/0958 8221.2012.735101)

Colpaert, J. (2013). Ontological specification of an authoring interface for creating sustainable language learning content. In Lung-Hsiang WONG, Chen-Chung LIU, Tsukasa HIRASHIMA, Pudjo SUMEDI and Muhammad LUKMAN (eds.). Proceedings of the 21st International Conference on Computers in Education. Indonesia: Asia-Pacific Society for Computers in Education, pp 644-653. ISBN 978-602-8040-71-6.

Colpaert, Jozef. (2014). Educational Engineering and Distributed Design. Research Report. Universiteit Antwerpen. $25 \mathrm{p}$.

Colpaert, J., Aerts, A. \& Oberhofer, M. (eds.). (2014). Research Challenges in CALL. Proceedings of the Sixteenth International CALL Conference, 7-9 July 2014. Antwerp: University of Antwerp. 400 p. ISBN 9789057284533. 
Cornillie, F., Clarebout, G., \& Desmet, P. (2012). Between learning and playing? Exploring learners' perceptions of corrective feedback in an immersive game for English pragmatics. ReCALL, 24(3), 257-278. doi:10.1017/S0958344012000146 http://journals.cambridge.org/abstract_ S0958344012000146

Cronbach, L.J. (1975). Beyond the two disciplines of scientific psychology. American Psychologist, 30(2), 116-27.

Dörnyei, Z., \& Ushioda, E. (Eds.). (2009). Motivation, language identity and the L2 self. Bristol, UK: Multilingual Matters.

Polsani, P. (2006). Use and Abuse of Reusable Learning Objects. Journal of Digital Information, North America, 3, feb. 2006. Available at: http://journals.tdl.org/jodi/index.php/jodi/article/ view/89/88. Date accessed: 4 June 2014.

Ryan, R., \& Deci, E. (2000). Self-determination theory and the facilitation of intrinsic motivation, social development, and well-being. American Psychologist, 55, 68-78.

van Doremalen, J. (2014). Developing automatic speech recognition-enabled language learning applications: from theory to practice (Doctoral dissertation). Nijmegen: Radboud Universiteit Nijmegen.

Van Laer, S., Beauchamp, G., \& Colpaert, J. (2012). Teacher use of the interactive whiteboards in Flemish secondary education-mapping against a transition framework. Education and Information Technologies, 1-15.

Venkatesh, V. (2000). Determinants of Perceived Ease of Use: Integrating Control, Intrinsic Motivation, and Emotion into the Technology Acceptance Model. Information Systems Research, 11(4), 342-365. http://dx.doi.org/10.1287/isre.11.4.342.11872.

Venkatesh, V., Thong, J.Y.L. \& Xu, X. (2012). Consumer Acceptance and Use of Information Technology: Extending the Unified Theory of Acceptance and Use of Technology (February 9, 2012). MIS Quarterly, 36(1), 157-178. Available at SSRN: http://ssrn.com/abstract=2002388. 